\title{
Research on the Operation and Development of Sports Fitness Industry Based on Internet Plus Era
}

\author{
Gong Yan \\ Jiangxi Science and Technology Normal University, Nanchang, Jiangxi, 330003
}

Keywords: Internet, Physical Fitness, Operation and Development

\begin{abstract}
The advent of the Internet era not only indicates the way for economic growth, but also brings new inspiration to the operation and development of sports fitness industry in China. In this paper, through the analysis of the development trend of sports fitness industry in the Internet plus era, to explore the challenges of sports fitness industry operation of the Internet plus era, and puts forward some suggestions, in order to promote the development of sports industry in the era of Internet plus.
\end{abstract}

\section{Introduction}

With the improvement of people's living standards, more and more people attach importance to the importance of physical fitness, and the sports fitness industry also develops rapidly. The development of the Internet has brought new changes to the sports and fitness industry, especially in the operation of physical fitness industry [1-2].

\section{The Trend of Sports Fitness Industry Operation Development Internet Plus Era}

\subsection{Individualization of fitness information service}

The personalization of fitness information service is mainly manifested in the convenience of the acquisition of fitness information and the more individuality of the fitness service. In the Internet environment, we can develop fitness records and fitness programs that meet user preferences according to user search habits and search records, and push users closer to the user's home or workplace [3]. Personalized fitness information provides users with a better user experience, and more close to the needs of the fitness.

\subsection{Scientific information service of fitness}

The progress of Internet technology has also established a relatively mature health resource pool, providing the public with a scientific health information consultation service. The establishment of more fitness information websites has provided network consultation services for the masses. Online fitness, Internet private education, remote fitness monitoring and other scientific means have been applied to the current development of sports fitness industry, which fully embodies the idea of "people first" [4]. Whether in the provision of fitness information or fitness methods, are fully reflected in the sports industry fitness to scientific development.

\subsection{The immediacy of fitness facilities}

The development of Internet promotes the combination of outdoor fitness and indoor fitness. More and more fitness app and fitness websites are being guided by private tutors and fitness workers. At the same time, because online can get professional fitness guidance and fitness advice, the traditional gymnasium by coach guidance fitness mode has also been a certain impact. In the Internet plus era of sports fitness industry operation embarked on a more scientific and healthy development road. 


\section{The Challenge of Operation of Sports Fitness Industry Internet Plus Era}

\subsection{Network information security can not be guaranteed}

At present, all kinds of fitness websites and fitness app have come online, and they have entered the life of people. However, due to the lack of legal management of the relevant web pages and app, the information of the users of the website may be stolen, which can not provide security for the information security of the large body builders [5]. At the same time, due to the complexity of the Internet environment, the lack of system control. Some wrongful people disguised as normal fitness sites to cheat users' information, causing huge risks to the security of personal information.

At the same time, because the sports security software itself has many security vulnerabilities, it is easily invaded by malicious software and virus. This may affect the user's normal use, cause the loss of the user, and affect the user experience of the software.

\subsection{The safety of fitness can not be guaranteed under the environment of network virtual space}

Compared with the traditional fitness industry, the trainer is responsible for the fitness goal of the fitness and the safety of the fitness, and the safety of physical fitness in the Internet age can not be guaranteed. It is possible for users to exercise regularly when they are exercising. If there is no professional guidance, they may damage the physical safety of the health workers. In order to gain benefits, some unlawfully pretended to be a trainer with fitness professional qualifications, and they do not have professional knowledge of fitness in themselves [6]. Under the guidance of the wrong sports fitness, not only can not play the proper effect of fitness, but on the body of the body caused damage.

Because of the virtual nature of the network, it is impossible to protect the rights and interests of the bodybuilders. For those who mislead the fitness people for their own interests, it is quite difficult for them to punish the injured persons, so they cannot be investigated for legal liability. The legal guarantee is also lagging behind, and it can not provide guarantee for the public health in time [7].

\subsection{The integration of mobile applications faces great challenges}

The growing popularity of smartphones and other mobile devices, sports mobile applications show a broad development prospects. The physical fitness APP promotes the organic interaction between the traditional sports fitness industry and the emerging media, and promotes the development of the Internet sports fitness [8]. Various mobile applications and related websites provide users with the discovery and recommendation of physical fitness knowledge. Related information of mobile application distribution in the app store, professional forums and social networks, in which all kinds of information diversity, heterogeneous and dynamic to the mobile application integration has brought great challenges, also increases the difficulty of physical fitness to obtain accurate information on the network.

The basic mathematics and related information of mobile applications often exist in different data sources. Functional information is often hidden in the unstructured information such as description information and user reviews of mobile applications, making information acquisition more difficult. But in the era of Internet, user preferences are constantly changing, leading to the ever-changing ranking of applications, making information acquisition for mobile applications more difficult.

\subsection{The defects of network fitness itself}

At present, the design of online fitness is mainly concerned with the interest of the user, and there is a big gap between the fitness effect and the practice of physical fitness. Online fitness is more of a sense of awareness that many users use online fitness app just to get fitness data in a circle of friends and perform self - expression.

At the same time, the self-fitness of the user has brought hidden dangers to the health of the body. 
There is a shortage of video playback or voice guidance, far from the effect of field guidance. Although some fitness private education can be good for teaching, but the network teaching and practical teaching are two concepts, and may not be the system of guidance on the fitness gym, compared with the actual teaching, the teaching effect may be less effective [9-10].

\subsection{Physical fitness information asymmetry}

In the Internet era, the sports fitness industry relies on the development of Internet information, but the information is complex on the Internet. Fitness workers can not find the most suitable fitness program. At the same time, the existence of various types of physical fitness app also makes it difficult for the fitness workers to choose. The information released by the gymnasiums on the fitness website is relatively poor, and the fitness people lack the understanding of these information. Only by user evaluation can we not know the real situation of the gymnasium. The asymmetry of physical fitness information leads to the lag of user information and may be deceived by the gym. Users can't get effective guidance and supervision after buying gym fitness service, or the fitness effect of gymnasium is not as good as users' expectations. Eventually, users will lose interest in fitness and stay away from the gym.

\section{Recommended Operating Sports Fitness Industry Internet Plus Era}

\subsection{Perfection of laws and regulations on physical fitness service in the Internet}

Internet technology has penetrated into every aspect of people's life. The state should take the Internet security obligation as a clear legal concept to join our tort law system. Physical fitness activities Internet plus the era of network activities for the media, only the safe use of platform service providers and users in the network security activities, to provide security for the Internet sports fitness.

At the same time, we will establish an access mechanism for Internet sports platform, filter information on sports fitness service on the Internet, and seal up the websites that are swindled in the name of sports websites, and punish the offenders according to law [11]. We should speed up the pace of legislation on the security supervision of mobile Internet and strengthen the law of personal information protection.

\subsection{Strengthening the research and development of mobile application integration technology}

Faced with a large number of distractions in mobile applications, we should integrate mobile applications and information, provide users with high-quality search recommendation services, and enhance the research and development of mobile application integration technology. In the integrated technology research and development activities, we should coordinate the supply and demand relationship between developers, mobile application platforms and the third party service platform, so as to provide better user experience for sports fitness providers.

\subsection{Perfecting the self-defects of the network fitness platform}

The government needs to develop the Internet fitness service market as a whole so that the Internet fitness service market can run healthily and reasonably. Integrate a variety of Internet fitness information, coordination of different sports fitness skills, all kinds of knowledge for organic combination [12-13]. Construct social fitness activities that are in line with the development of public interest and dominated by the government. We should promote the improvement of network fitness services in terms of resources, capabilities, knowledge and service levels, improve the defects of the network fitness platform, and improve the effect of network fitness teaching.

\subsection{Strengthen the public's knowledge of fitness}

In the face of the complex knowledge of fitness on the network, it is not only necessary for the government and the network platform to discriminate the knowledge, but also the user's own ability to identify. Therefore, it is necessary to improve the public awareness of fitness knowledge, improve the user's ability to identify fitness knowledge and be able to choose fitness methods 
suitable. In this way, the public will not be blind to the selection of fitness methods and fitness sites, and the risk factor of fitness will be reduced to a minimum.

\section{Conclusion}

In recent years, the Internet has brought great changes to people's life. In order to adapt to these changes, the convenience brought about by the Internet is used. In terms of operation of sports fitness industry, we should improve laws and regulations of Internet sports fitness service, strengthen the research and development of mobile application integration technology, improve the defects of network fitness platform, and enhance the public's knowledge in fitness. Through these efforts, promote the development of sports industry in the era of Internet plus.

\section{References}

[1] Zhang B, Rao R. Sports Industry Development Strategy Study under the Background of “Internet plus” [J]. Bulletin of Sport Science \& Technology, 2017.

[2] Xu Z. Fuzzy Comprehensive Evaluation on China's Sports Industry Development Research in the Backgrounds of Leisure Era[J]. Open Cybernetics \& Systemics Journal, 2015, 9(1):1672-1676.

[3] Pan Y J, Ding X, Xu C, et al. Innovation and Prospect of Sports Industry Reform in the Era of Internet -Taking Sports APP Operation as an Example[C]// International Conference on Innovations in Economic Management and Social Science. 2017.

[4] Miao H. Study on the Relationships between Development of Sports Industry and Economic Environment[C]// Fifth International Conference on Measuring Technology and Mechatronics Automation. IEEE, 2013:1103-1106.

[5] Wei T, Lianggang L I, Xiao W. A research on development thoughts and countermeasures to the elderly fitness service industry_ _ based on the background of our country healthy aging[J]. Liaoning Sport Science \& Technology, 2016.

[6] Zhu Z. Study on the Sustainable Development of Sports Fitness Clubs in China[J]. Journal of Harbin Sport University, 2014.

[7] Liu X, Zhang Y. SWOT Analysis on the Development of China's Sports Industry in the Era of Negative Interest Rate[J]. Hubei Sports Science, 2016.

[8] Jing H, Han Y, School of P E, et al. Restrictions of Sports Facility Standards on the Development of National Fitness and the Countermeasures: Based on the Standards and the Liabilities for Injury[J]. Journal of Tianjin University of Sport, 2013.

[9] Yang F J, Chen Z H, University J. Research on Data Analysis and Application of Sports in the Big Data Era[J]. Journal of Xian University, 2017.

[10] Wang Z H, Yan L I. Strategic Design and Implementation Path of Sports Industry of Hebei Provincial Sports Fitness and Leisure Circle around Beijing and Tianjin[J]. Journal of Hebei Institute of Physical Education, 2015.

[11] Tang X. Research on Development of Sports Fitness and Entertainment Industry in Yongchuan [J]. Bulletin of Sport Science \& Technology, 2014.

[12] Ding B, Ma Y. Analysis on Development of National Fitness Movement Based on College Sports Resource[M]// Informatics and Management Science V. Springer London, 2013:643-650.

[13] Yin J H. Reflection on Development of Outdoor Fitness Recreational Sports Industry in Inner Mongolia[J]. China School Physical Education, 2014. 